\title{
Treatment of pulping effluents by using alum and clay - Colour removal and sludge characteristics
}

\author{
FB Dilek* and S Bese \\ Middle East Technical University, Environmental Engineering Department, 06531, Ankara, Turkey
}

\begin{abstract}
The effect of clay addition during alum coagulation, on the removal of colour from pulp-and-paper industry wastewaters, was investigated. Four types of clay, namely beige-and brown-sepiolites, calcium- and sodium-bentonites of different mesh sizes were used. Different quantities of alum and clay were applied, either singly or in combination, to the effluents of the wood-based pulpand-paper mill. Colour of the treated wastewater, the sludge volume index (SVI) and sludge cake resistance (SCR) of the sludge produced were monitored. It was observed that the clays tested were not efficient in colour removal when they were applied on their own. When clay was added along with alum, a certain increase in colour removal efficiency was obtained as compared to alum alone. When alum was used in conjunction with clay, settling characteristics of the sludge produced improved substantially, in terms of both SVI and SCR. Acid activation of the clays did not improve the colour removal efficiency further. However, acid activation of sodium bentonite caused the SVI and SCR values to improve considerably compared to virgin sodium bentonite. Use of different mesh sizes of clays did not exert any significant effect on the colour removal. However, it did exert significant effects on SVI and SCR values as such that the increase in mesh size caused the SVI values to decrease and the SCR values to increase.
\end{abstract}

\section{Introduction}

The problem of colour removal from pulp-and-paper mill waste has been a subject of great consideration and investigation in the last few decades. The colouring body present in the wastewater from pulp-and-paper mill is organic in nature and is comprised of wood extractives, tannins, resins, synthetic dyes, lignin and its degradation products formed by the action of chlorine on lignin (Srivastava et al., 1984; Rao and Dutta, 1987; Manivasakam, 1987). Discharge of coloured pulping effluents to the receiving waters inhibits photosynthetic activity of aquatic biota by reducing the penetration of sunlight, besides their direct toxic effects on biota (Zanella and Berben, 1980; Walden and Howard, 1981). The colour compounds also chelate metal ions and may import contamination by heavy metals (Srivastava et al., 1984). It is imperative that the colour present in pulp-and-paper mill effluents be removed before being discharged into receiving waters.

Several studies have been carried out concerning the decolorisation and/or treatment of such waters by biological methods (Bauman and Luts, 1974; Joyce et al., 1979; Bryant et al., 1987; Skogman and Lammi, 1988). These methods such as aerated lagoons and activated sludge systems do not cause sufficient decolorisation mainly because of the high stability of lignin and its derivatives (Livernoche et al., 1983; Archibald and Roy-Arcand, 1995). It has also been investigated by several researchers that kraft mill effluents can be partly decolorised by white-rot fungi (Eaton et al., 1980; Livernoche et al., 1983; Prouty, 1990; Gokcay and Dilek, 1994). However, Gokcay and Dilek (1994) pointed out that this treatment is economically unfeasible due to the need for high glucose concentration by the fungus. They have also reported that the fungus was not effective when bleachery effluents were present.

\footnotetext{
* To whom all correspondence should be addressed.

盄90-312-2105877; fax 90-312-2101260; e-mail: fdilek@metu.edu.tr

Received 23 August 2000; accepted in revised form 30 January 2001.
}

Several physico-chemical colour removal methods such as chemical precipitation, rapid sand filtration, membrane processes and adsorption have also been developed (Springer, 1985). Adsorption and membrane processes, although they are efficient, are expensive (Manjunath and Mehrotra, 1981). The application of electrochemical methods is an another way to treat the wastewaters from the cellulose-paper production (Christoskova and Lazarov, 1988). This method guarantees high treatment efficiency, but its effectiveness depends on the type of electrodes, the construction of electrocoagulators, and the conditions under which the process is run. Chemical precipitation, using alum, ferric chloride, and lime has been studied extensively (Lathia and Joyce, 1978; Dugal et al., 1976; Joyce et al., 1979; Srivastava et al, 1984; Beulker and Jekel, 1993; Stephenson and Duff, 1996); in spite of short detention times and low capital costs, there are some drawbacks reported, such as high cost of chemicals for precipitation as well as for $\mathrm{pH}$ adjustment, voluminous sludge production due to heavy dosages, problems associated with dewatering and disposing of generated sludge and high residual cation levels, so that their colour, which remain in the supernatant (Stephenson and Duff, 1996; Srivastava et al., 1984). However, as discharge standards become increasingly strict, chemical precipitation may have a role in the treatment of pulping effluents either upstream of biological treatment or as a polishing operation downstream of biological treatment to remove recalcitrant compounds (Stephenson and Duff, 1996).

From the foregoing discussion, it is clear that all treatment methods in use have some drawbacks, and there is a need to look for other alternative methods. In the literature, there is some evidence that clays, when used in conjunction with alum, result in improved colour removals and sludge characteristics, as compared to alum alone (Mittal and Mehrotra, 1981). However, there are no detailed studies in the literature about the detailed investigation of the subject. So, it is the aim of this study to investigate the decolorisation of wood-based pulp-and-paper industry wastewater by using Turkish clays as an aid to the traditional coagulant, alum. 


\section{Experimental}

\section{Wastewater}

Wastewater was obtained from the Dalaman Pulp-and-paper Plant owned by the General Directorate of the Turkish State Pulp-andpaper Works (SEKA). Pine softwood is used as the raw material in the plant. The Kraft process is employed for pulp production and cellulose is cooked in vertically-operated Camry pressurised cookers. The plant produces 100000 t of cellulose annually. A sixstage bleachery process is applied to the cooked pulp in the following sequence: Chlorination (C), Extraction with caustic soda (E), Hypochlorite (H), Chlorine dioxide(D), Extraction(E), Chlorine dioxide (D) stages, designated as CEHDED. Wastewater has the following characteristics (expressed in $\mathrm{mg} / \ell$ ) COD: 260, suspended solids: 10, colour: 1150 Pt-Co: pH 6 to 8 . From the previous study, it is known that a great portion of lignin derivative aromatic groups present in wastewater of chlorination unit of the Dalaman Cellulose Production Plant has a molecular size greater than $30000 \mathrm{~g} / \mathrm{gmol}$ MW (Gokcay et al., 1996).

\section{Source and types of clays}

Clays, namely, sodium-bentonite, calcium-bentonite, beige sepiolite and brown sepiolite, that are obtained from the Institute of Mineral Research and Exploration, Turkey (MTA) were crushed and sieved to two different mesh sizes. Na-bentonite was available only in one size (200 mesh) (Table 1).

\begin{tabular}{|l|l|}
\hline \multicolumn{2}{|c|}{ TABLE 1 } \\
Particle size of the clays tested \\
\hline Clay type & Clay mesh size \\
\hline Brown sepiolite $(\mathrm{BrS})$ & $\begin{array}{l}+65 \text { and } 100 \\
+60 \text { and } 100 \\
\text { Beige sepiolite }(\mathrm{BeS}) \\
\text { Sodium-bentonite }(\mathrm{NaB}) \\
\text { Calcium-bentonite }(\mathrm{CaB})\end{array}$ \\
\hline
\end{tabular}

\section{Pretreatment of clays}

$\mathrm{BrS}(+100), \mathrm{NaB}(+200)$ and $\mathrm{CaB}(+200)$ were pretreated with acids. The "dry activation process" suggested by Juang et al. (1997) was applied. The acid treatment has the effect of removing cations from the crystal structure to give a clay with improved porosity and higher surface area which enhance adsorption capacity, and enhanced chemical properties such as ion exchange capacity and catalytic activity (Kendall, 1996).

\section{Analysis}

The colour was measured as Pt-Co unit by using a HACH DR/2000 Spectrophotometer that had been calibrated against platinumcobalt (Pt-Co) colour standards. The sludge volume index of samples was determined according to Standard Methods (1995). The specific cake resistance of sludge was determined by conducting batch filtration tests.

\section{Experiments}

Alum and/or clay coagulation tests were conducted using standard jar test equipment. Using $10000 \mathrm{mg} /$ / stock solution of commercially available alum $\left(\mathrm{Al}_{2}\left(\mathrm{SO}_{4}\right)_{3} \cdot 18 \mathrm{H}_{2} \mathrm{O}\right)$, an appropriate alum dosage was applied. Clay was added directly to the wastewater. The experiments were conducted at $\mathrm{pH} 7$ that was determined as the optimum $\mathrm{pH}$ for colour removal, prior to the experimentation. So, no $\mathrm{pH}$ adjustment was carried out during the experiments as the natural $\mathrm{pH}$ of the wastewater was already neutral. The wastewater, alum and clay mixture was stirred at a high speed $(120 \mathrm{r} / \mathrm{min})$ for $3 \mathrm{~min}$ and then at a low speed $(20 \mathrm{r} / \mathrm{min})$ for $15 \mathrm{~min}$ as described in Standard Methods, 1995). The sludge was allowed to settle for 1 $\mathrm{h}$ and the supernatant was obtained by filtering through $\mathrm{GF} / \mathrm{C}$ filter. Then it was analyzed for its colour value. The characteristics the sludge produced were measured in terms of sludge volume index (SVI) and sludge cake resistance (SCR).

Two selected levels of alum and clay concentration were studied in combination (Table 2). These levels were selected on the basis of results obtained with sole alum and clay applications as the doses that yield maximum colour removals. The results of these experiments are not presented here.

\begin{tabular}{|c|c|c|}
\hline \multicolumn{3}{|c|}{ TABLE 2 } \\
\hline \multicolumn{2}{|c|}{ Selected levels of alum and clays } \\
\hline Alum or clay & Low level $(\mathrm{mg} / \ell)$ & High level $(\mathrm{mg} / \ell)$ \\
\hline Alum & 200 & 300 \\
$\mathrm{BrS}$ & 400 & 2000 \\
$\mathrm{BS}$ & 200 & 1000 \\
$\mathrm{NaB}$ & 100 & 1000 \\
$\mathrm{CaB}$ & 100 & 1000 \\
\hline
\end{tabular}

\section{Results and discussion}

\section{Colour removal}

In these experiments, selected doses of alum and clay(s) were applied in combination in order to observe the effect of clay on alum coagulation for the removal of colour. Possible interactions expected are:

- Colour (lignin) - Clay interaction: Both lignin and clay are negatively charged, therefore an interaction between them is difficult. Colour removal could occur by the adsorption onto the clay surface due to its large specific surface area.

- Colour (lignin) - Alum interaction (Hydrophilic colloidcoagulant): Colour-alum interaction results in the formation of flocs and colour is either precipitated or adsorbed by them.

- Clay-colour (lignin) - Alum interaction: Clays of the type bentonites and sepiolites increase colloidal concentration and interparticle contacts. So, destabilisations by adsorption and charge neutralisation become possible even at lower dosages of coagulant.

Colour removal results obtained are presented in Fig. 1 in a comparative manner. As can be seen from this figure, in general, the removal of colour was increased by the addition of clay(s) together with alum when compared to the addition of alum alone. Combinations with higher alum dosages yielded higher colour removals compared to those with lower alum dose in all cases. This 

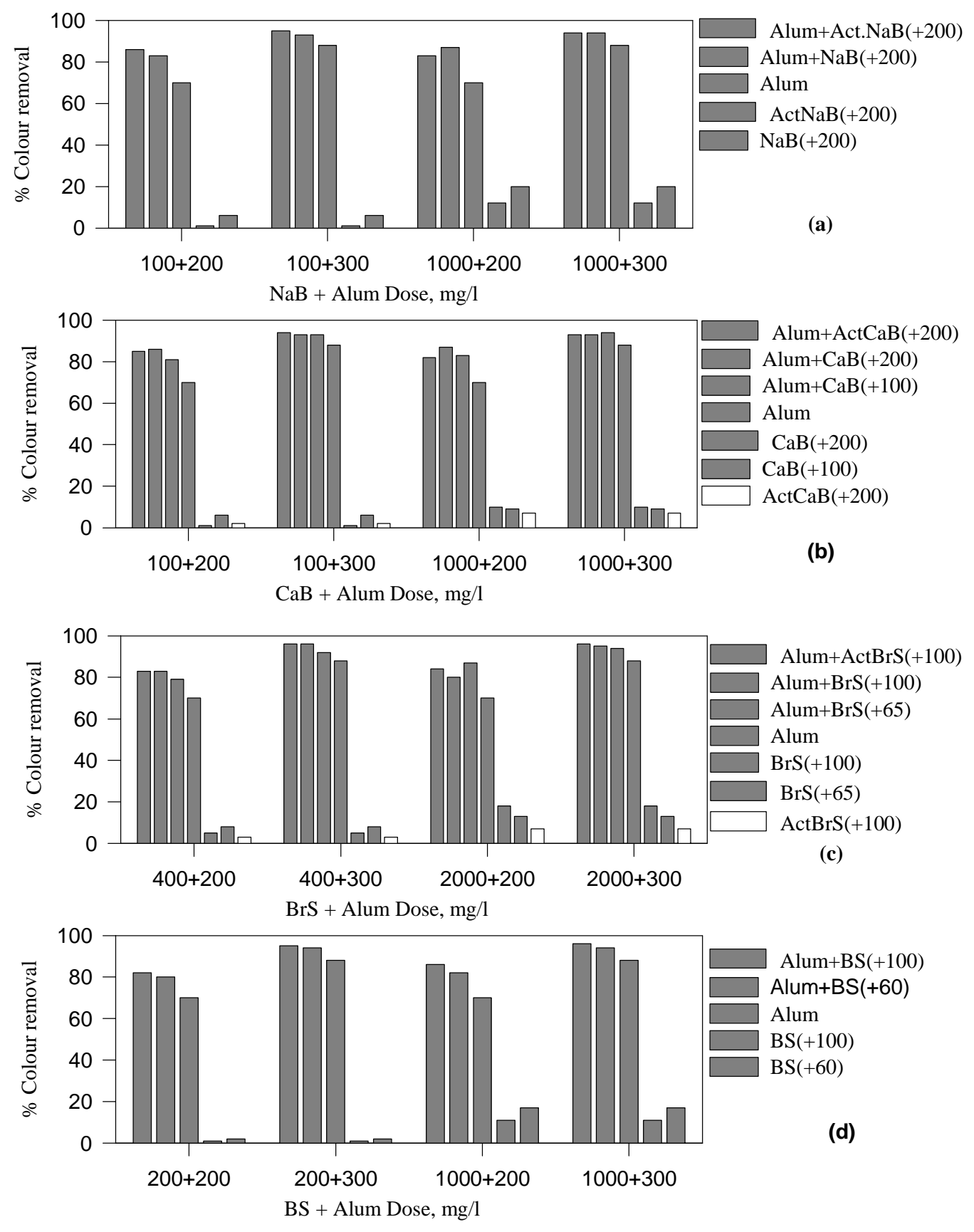

Figure 1

\% Colour removal vs. (a) NaB+alum; (b) $\mathrm{CaB}+a l u m$; (c) BSR+alum; (d) BS+alum dose

was attributed to the relatively higher colour removal value obtained at higher alum dose, namely $300 \mathrm{mg} / \ell$, alone. On the other hand, the stimulatory or positive effect of clay on colour removal was more observable at combinations with lower alum dose than at those with higher alum dose. It was interesting to observe that this stimulatory effect was almost independent of the clay type, clay mesh size and activation (Fig. 1a, b, c, d). In fact, based on the findings of Kendall (1996), it was our expectation that the colour removal could be improved with acid activation. However, it did not. This could be attributed to the superior effect of alum compared to clay on colour removal.

\section{Settleability of sludge}

In order to observe the settling characteristics of the sludge produced, SVI determinations were carried out. The results obtained are shown in Fig. 2. As can be seen from this figure, SVI values improved remarkably when alum was introduced together with clay(s), compared to alum addition only. This improvement was much more noticeable at combinations with high clay dose.

Figure $2 \mathrm{a}$ presents the results obtained for the clay $\mathrm{NaB}(+200)$. The beneficial effect of $\mathrm{NaB}(+200)$ increased considerably with acid activation (Fig. 2a). It can also be seen from this figure that $300 \mathrm{mg} / \ell$ alum dose yielded higher SVI values than $200 \mathrm{mg} / \ell$, either in single or combination cases. Therefore, it can be said that there 


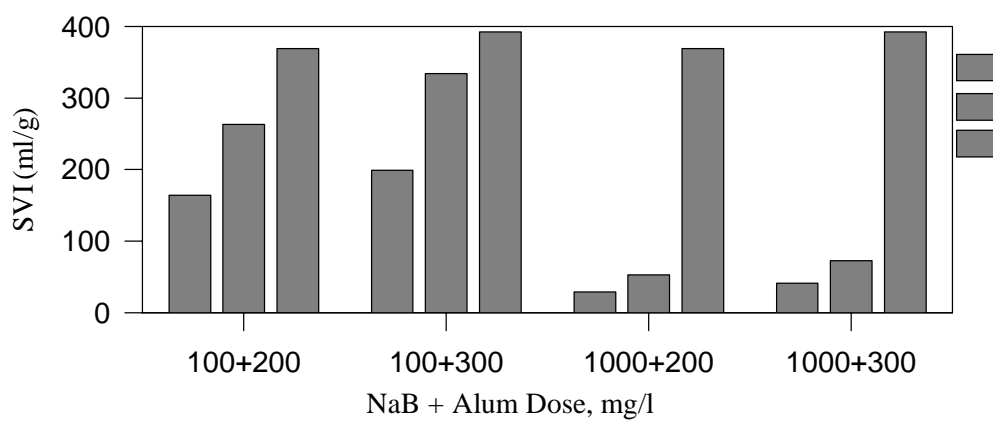

Alum + ActNaB $(+200)$

Alum $+\mathrm{NaB}(+200)$

Alum

(a)

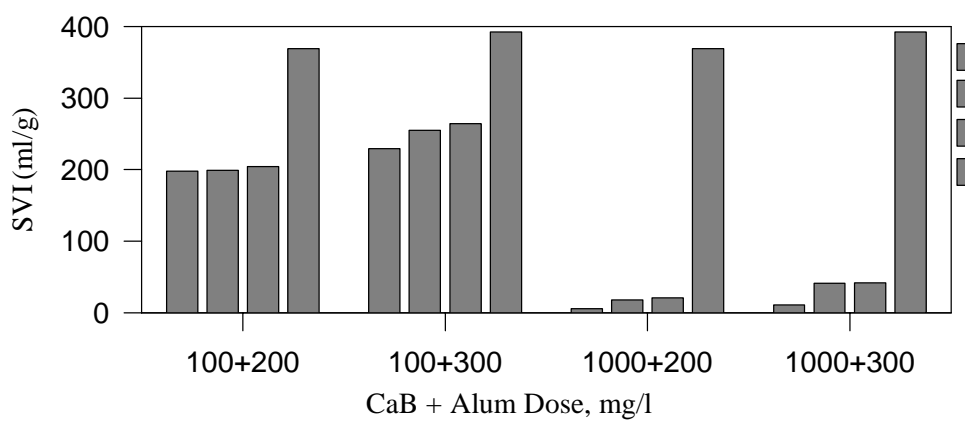

Alum $+\mathrm{ActCaB}(+200)$

Alum $+\mathrm{CaB}(+200)$

Alum $+\mathrm{CaB}(+100)$

Alum

(b)

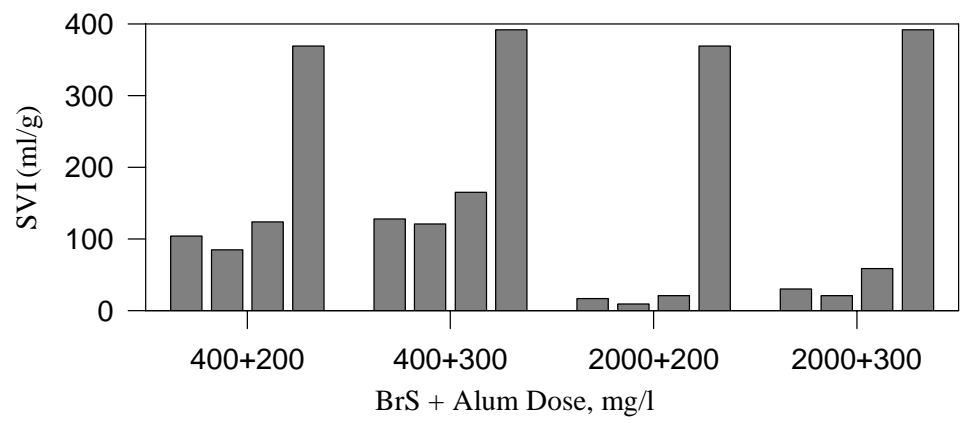

Alum + ActBrS $(+100)$

Alum $+\mathrm{BrS}(+100)$

Alum $+\mathrm{BrS}(+65)$

Alum

(c)

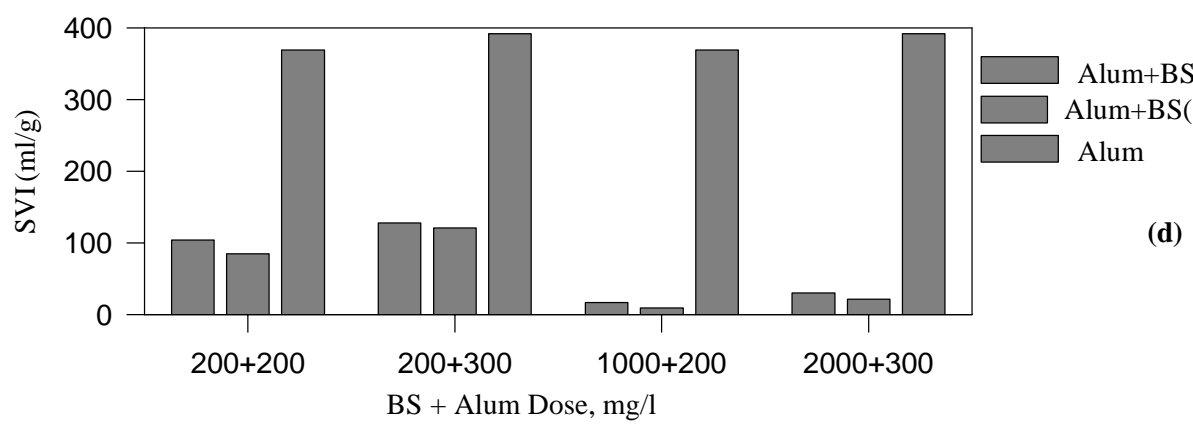

Figure 2

SVI vs. (a) NaB+alum; (b) CaB+alum; (c) BSR+alum; (d) BS+alum dose

is a negative effect of alum on the settleability of sludge.

Figure $2 b$ presents the results obtained for $\mathrm{CaB}$. Comparison of the results obtained at two different mesh sizes of $\mathrm{CaB}$ showed that the SVI values decreased very slightly with increasing mesh size. It was also observed that the SVI value obtained for alum + activated $\mathrm{CaB}(+200)$ was lower than for alum $+\mathrm{CaB}(+200)$.

In the case of clay BrS, there was a slight decrease in SVI with increasing mesh size (Fig. 2c). On the other hand, SVI values obtained for alum + activated $\mathrm{BrS}$ were slightly higher than for alum $+\mathrm{BrS}(+100)$ and slightly lower than for alum $+\mathrm{BrS}(+65)$. Comparison with $\mathrm{NaB}$ and $\mathrm{CaB}$ cases indicated that the SVI values for alum $+\mathrm{BrS}$ were lower especially for combinations with a low clay dose. Similar to the results obtained for $\mathrm{CaB}$, no change or a very slight decrease in SVI values was observed with increasing BS mesh size (Fig. 2d).

In order to observe the settling characteristics of the sludge produced, SVI determinations were carried out. The results obtained are shown in Fig. 2. As can be seen from this figure, SVI values were improved.

Comparison of all clay types tested revealed that, in terms of degree of improvement on SVI, the virgin clay types could be rated as $\mathrm{BS}>\mathrm{BrS}>\mathrm{CaB}>\mathrm{NaB}$ for both their high and low dose cases. However, the activated clays exerted a different pattern, which varies with dose. For example, for the low levels of clays, the order seemed to be $\mathrm{BrS}>\mathrm{NaB}>\mathrm{CaB}$, whereas for the high levels of clays it seemed to be $\mathrm{CaB}>\mathrm{BrS}>\mathrm{NaB}$. 


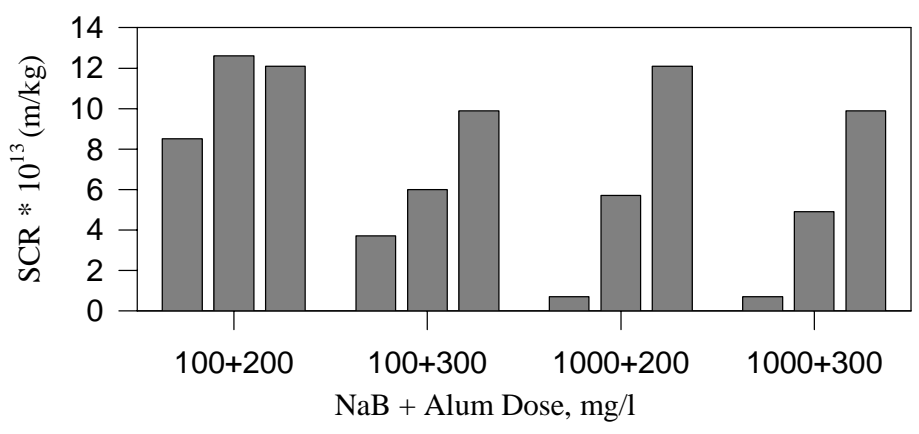

Alum + ActNaB $(+200)$

Alum $+\mathrm{NaB}(+200)$

Alum

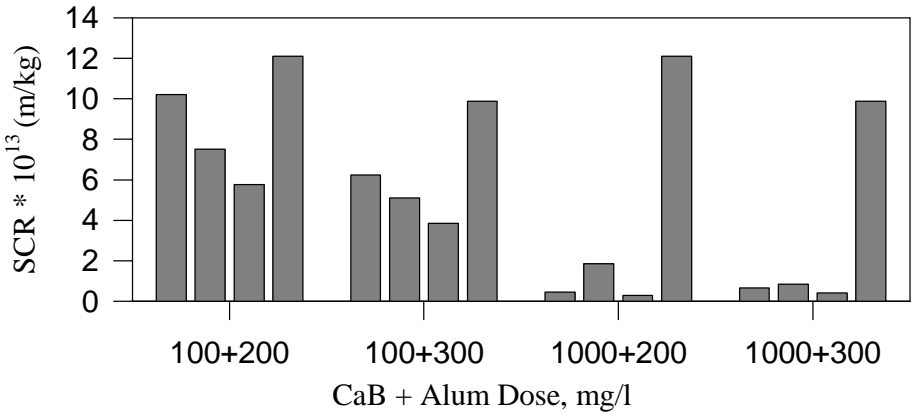

Alum $+\mathrm{ActCaB}(+200)$

Alum+CaB $(+200)$

Alum $+\mathrm{CaB}(+100)$

Alum

(b)

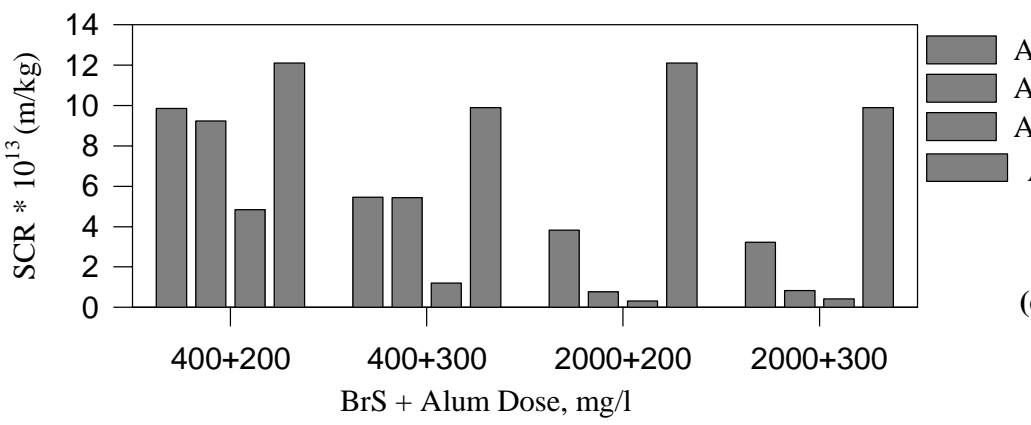

Alum+ActBrS $(+100)$

Alum $+\mathrm{BrS}(+100)$

Alum+BrS(+65)

Alum

(c)

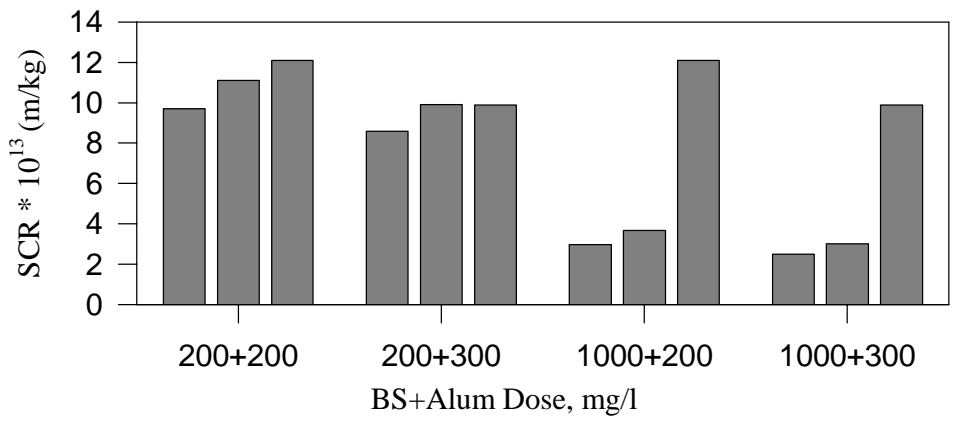

Alum+BS $(+60)$

Alum+BS $(+100)$

Alum

(d)

Figure 3

SCR vs. (a) NaB+alum; (b) CaB+alum; (c) BSR+alum; (d) BS+alum dose

\section{Dewaterability of sludge}

In an attempt to observe the effect of clay addition as an aid to alum on the dewaterability characteristics of the sludge, SCR measurements were performed. The results are given in Fig. 3 . The SCR determinations were also carried out for the sludges corresponding to alum doses only, namely 200 and $300 \mathrm{mg} / \ell$. The SCR of the former and latter alum dose was determined to be $1.21 * 10^{14}$ and $0.99 * 10^{14} \mathrm{~m} / \mathrm{kg}$, respectively. These values are close to those reported by Degremont (1991).

As can be seen from Fig. 3, the clay addition exerted a positive effect on the dewaterability of the sludge, in general. This is similar to the observation by Degremont (1991). This improvement was more pronounced in combinations with higher clay dosages. Also, in accordance with the observations of Gala et al. (1981) who claimed that sludge cakes (fine coal) formed from higher mesh sizes were more difficult to dewater and the increase in mesh size also caused the SCR to increase. However, it should be stressed here that the sludge materials compared are different, so the effects are not directly comparable.

Figure 3 a shows the results obtained for $\mathrm{NaB}$, with and without pretreatment, in combination with alum. It is noticed that the addition of clay resulted in a decrease in the SCR values, except for $100 \mathrm{mg} / \ell$ clay $+200 \mathrm{mg} / \ell$ alum combination, at which almost no alteration was observed. This improvement observed is contrary to the findings of Piirtola et al. (2000) who reported a negative effect 
of $\mathrm{NaB}$ on the alum sludge filterability. A comparison between activated $\mathrm{NaB}$ and virgin $\mathrm{NaB}$ cases revealed that the activation did result in the remarkable decrease in SCR. Also, for the other combinations, acid activation yielded greater decreases in SCR compared to no pretreatment.

The SCR values for the combinations of alum and $\mathrm{CaB}$ are given in Fig. 3b. The positive effect of $\mathrm{CaB}$ addition was obvious in the SCR values. A comparison between two mesh sizes studied showed that there is a slight increase in SCR values with increasing mesh size. However, the acid activated $\mathrm{CaB}(+200)$ caused the SCR values to increase at low clay dose cases, whereas a slight decrease was observed at the high clay dose cases.

The SCR results for BrS are presented in Fig. 3c. An increase in SCR was observed with increasing mesh size. The SCR values of acid activated $\mathrm{BrS}+$ alum combination were higher than those of virgin $\mathrm{BrS}$ at high clay doses, whereas almost no effect of acid activation was observed at low clay dose cases.

Figure $3 \mathrm{~d}$ presents the results obtained for BS in combination with alum. As can be deduced from this figure, the SCR values were improved at high clay doses compared to alum only. At low clay dose combinations almost no, or only very slight effect was observed.

The clays used in this study could be rated for their ability to improve the sludge dewaterability in descending order as $\mathrm{CaB}>$ $\mathrm{BrS}>\mathrm{NaB}>\mathrm{BS}$ for both low and high doses of virgin clay; as $\mathrm{CaB}$ $>\mathrm{NaB}>\mathrm{BrS}$ for high doses of activated clay and as $\mathrm{NaB}>\mathrm{BrS}>$ $\mathrm{CaB}$ for low doses of activated clay.

\section{Conclusion}

The following conclusions can be drawn from this study:

- Although alum was observed to be an effective coagulant that provided up to $88 \%$ colour removal, it yielded a voluminous sludge with poor settling characteristics.

- Addition of clay alone resulted in very poor colour removal efficiencies.

- The use of clay as a coagulant aid for alum improved the colour removal efficiency to some extent, especially at combinations with low alum dose, for the clays tested.

- In general, significant decreases in SVI and SCR were observed with clay addition. The addition of clay produced a more compact floc with improved settling at lower alum dosages.

- Use of different mesh sizes of clays did not exert any significant effect on the colour removal. However, it did exert significant effects on SVI and SCR values as such that the increase in mesh size caused the SVI values to decrease and the SCR values to increase.

\section{References}

ARCHIBALD F and ROY-ARCAND L (1995) Photodegradation of high molecular weight kraft bleachery effluent organochlorine and color. Water Res. 29 (2) 661-669.

BEULKER S and JEKEL M (1993) Precipitation and coagulation of organic substances in bleachery effluents of pulp mills. Water Sci. and Technol. 27 (11) 193-199.

BRYANT CW, AMY GL and ALLEMAN BC (1987) Organic halide and organic carbon distribution and removal in a pulp and paper wastewater lagoon. J. of Water Pollut. Control Fed. 10 890-896.
CHRISTOSKOVASG and LAZAROV LD (1988) Electrochemical method for purification and discolouration of cellulose-paper industry wastewaters. Environ. Prot. Eng. 14 (3-4) 69-76.

DEGREMONT (1991) Water Treatment Handbook (6th edn.) Vol 1-2, Paris.

DUGAL HS, CHURCH JO, LEEKLEY RM and SWANSON JW (1976) Colour removal in a ferric chloride-lime system. TAPPI J. 59 (9) 71-74.

EATON D, CHANG HM and KIRK TK (1980) Fungal decolorization of kraft bleach effluents. TAPPI J. 63 103-106.

GALA HB, KAKWANI R, CHIANG SH, TIERNEY JW and KLINZING GE (1981) Filtration and dewatering of fine coal. Sep. Sci. and Technol. 16 (10) 1611-1632.

GOKCAY CF and DILEK FB (1994) Treatment of effluents from hempbased pulp and paper industry II. Biological treatability of pulping effluents. Water Sci. Technol. 29 (9) 161-163.

GOKCAY CF, YETIS U and DILEK FB (1996) Final Report of Characterization and Biological Treatability Project for Turkish State Pulp and Paper Industry (SEKA) Chlorinated Wastewaters. Project No 93-03-11-01-09, METU Environ. Eng. Dept., Ankara, Turkey.

JOYCE TW, DUBEY GA and WEBB AA (1979) The effect of biological treatment on the lime precipitation colour removal process. TAPPI J. 62 (12) 107-109.

JUANG RS, WU FC and TSENG RL (1997) The ability of activated clay for the adsorption of dyes from aqueous solutions. Environ. Technol. 18 525-531.

KENDAL T (1996) Industrial Clays. Industrial Minerals Information Ltd., London.

LATHIA SG and JOYCE TW (1978) Removal of colour from carbonate pulping effluent - The calcium-magnesium coagulation process. TAPPI J. 61 (10) 67-70.

LIVERNOCHE D, JURASEK L, DESROCHERS $M$ and DORICA J (1983) Removal of colour from Kraft mill wastewaters with cultures of white-rot fungi. Biotechnol. Bioeng. 25 2055-2065.

MANISAVAKAM N (1987) Industrial Effluents - Origin Characteristics, Effects. Analysis and Treatment. Sakthi Publication, Kovaipudur.

MANJUNNATHDL and MEHROTRA I (1981) Removal of reactive dyes using alum lignin sludge. Indian J. Environ. Health 23 (4) 309-315.

MITTAL AK and MEHROTRA I (1981) Decolorisation of pulp and paper mill waste using alum and clay. Indian J. Environ. Health 23 (3) 203214.

PIIRTOLA L, UUSITALO R and VESILIND A (2000) Effect of minerals and cations on activated and alum sludge settling. Water Res. 34 (1) 191-195.

PROUTY AG (1990) Bench-scale development and evaluation of a fungal bioreactor for colour removal from bleach effluents. Appl. Microbiol. and Biotechnol. 32 490-493.

RAO MN and DUTTA AK (1987) Waste Water Treatment. Oxford and IBH Publishing Co. Pvt. Ltd, New Delhi.

SKOGMAN R and LAMMI R (1988) The efficiency of a biological activated sludge treatment plant with extended aeration. Water Sci. and Technol. 20 (1) 65-72.

SPRINGER A (1985) Industrial Environment Control, Pulp and Paper Industry. John Wiley, New York.

SRIVASTAVA KA, GUPTA SK and IYER MVS (1984) Colour removal from paper mill waste. J. of Inst. Public Health Eng. India, Part 2/3, 5964.

STANDARD METHODS (1995) Standard Methods for Examination of Water and Wastewater (19 ${ }^{\text {th }}$ edn.), American Public Health Association/ American Water Works Association/Water Pollution Control Federation, Washington DC, USA.

STEPHENSON RJ and DUFF SJB (1996) Coagulation and precipitation of a mechanical pulping effluent - I. Removal of carbon, colour and turbidity. Water Res. 30 (4) 781-792.

WALDEN CC and Howard TE (1981) Toxicity of pulp and paper mill effluents-a review. Pulp and Pap. Canada 82 (4) T143-T146.

ZANELLA EF and BERBEN SA (1980) Evaluation of methodologies for the determination of acute toxicity in pulp and paper effluents. TAPPI J. $63(3) 77-82$. 